\title{
Investigation of Loss-of-Mains Detection on Induction Generators Based on Simple Reactive Power Changes Detection
}

\author{
M. Isnaeni B.S, F. Danang Wijaya, Eka Firmansyah \\ Department of Electrical Engineering and Information Technology, Faculty of Engineering, Gadjah Mada University, \\ Jl. Grafika 2, Yogyakarta, Indonesia \\ E-mail: isnaeni@ugm.ac.id
}

\begin{abstract}
A self-excited induction generator (SEIG) is widely used in micro hydropower plants. Generally, in Indonesia, the plant is integrated to a secondary distribution line and acts as a distributed generation (DG). If the distribution line is disconnected from the grid (loss-of-mains, LoM), then the plant must be immediately isolated before the distribution network contact equipment closes back in an out-of-synchronous mode. Voltage relays and frequency relays are commonly used to detect the occurrence of LoM on plants using SEIG. However, those relays are unable to detect all of the LoM events. This paper describes the excitation capacitor sizing strategy so that the direction of the reactive power flow changes in the event of a LoM. The change of direction of reactive power flow was used as an indicator of the occurrence of LoM. Detection of the direction of reactive power flow was done by manipulating the multiplication of instantaneous voltage and current. The result of excitation capacitor determination and LoM detection method was simulated using SIMULINK-Matlab. The simulation results showed that the proposed method could detect LoM, which could not be detected either by voltage relays or by frequency relays. The disadvantage of this method was not able to detect the LoM if the load and the power grid were capacitive. However, it is almost certain that the load and the distribution network are always inductive. The results of this study can be used as a direction for the application of LoM protection on SEIG.
\end{abstract}

Keywords - Loss-of-mains; SEIG; excitation capacitor; reactive power flow.

\section{INTRODUCTION}

The integration of renewable energy generation with the power system is seen as one of the solutions to meet the increasing power demand [1], [2]. Therefore, there is an increase in distributed generation (DG) penetration in power distribution systems. The squirrel-cage induction generator is widely used in micro-hydro power plants (MHPs) because it is easier to obtain in the market, cheaper, smaller physical size, and easier to maintain [2] [4]. The induction generator is excited from the capacitor installed in the terminal. When the rotor starts to rotate, the remaining magnet produces a small voltage on the stator. The capacitor that gets a small voltage will generate a current and then magnify the voltage across the stator. The process continues until the terminal voltage reaches a particular value. This phenomenon is known as self-excitation capacitors, and the induction generator is named as SEIG (self-excited induction generator) [3], [4].

One important issue on DG is islanding detection or loss of mains (LoM) detection. LoM occurs when part of the distribution network is electrically isolated from the power system, but it is still connected to the DG generator $[5,6]$. LoM is also called unintentional islanding. In general, LoM events occur because of short-circuiting interruptions in the distribution network. DG must be disconnected no later than 2 seconds after the LoM event [7].

LoM detecting techniques are grouped into local detection methods based on the DG side state and remote detection methods based on the state of the network side (utility). The local detection methods are grouped into passive methods based on measurements of the electric parameter at the plant, and active methods based on the injection of the detection signal at the generator [8],[9]. The remote detection method is very reliable but expensive and susceptible to network distribution configuration changes [10]-[12]. The active local methods are also reliable but may affect the protection system [13]-[15]. The passive method is a fast detection method and does not cause a disturbing signal, but has a large non-detection zone (NDZ) [16], [17].

LoM protection relays commonly used in micro-hydro plants are over/under frequency (OF/UF) and over/under voltage $(\mathrm{OV} / \mathrm{UV})$. However, these protection relays have limitations in detecting LoM [18], [19]. LoM detection using 
OF/UF and OV/UV relays are a passive method. There are certain LoM conditions that are in the detection zones of the relays. If there is only a small imbalance between the output power of the generator and the load, then the relays are unable to detect the LoM event.

Induction generator requires reactive power for excitation. In a stand-alone mode operation, reactive power is supplied from locally mounted capacitors. The size of the capacitor affects the magnitude of the voltage and the frequency [20], [21]. In an on-grid mode operation, the reactive power can be supplied from the grid or the locally mounted capacitors, or a combination of local capacitors and grids. Since the main function of the local capacitor is to excite the generator, the local capacitor is called the excitation capacitor. In this paper, it is proposed to reduce the reactive power of the excitation capacitor so that the reactive power of the excitation generator is mainly supplied from the excitation capacitor and a small portion is supplied from the grid. The size of the excitation capacitor is determined in such a way that under normal conditions and within the normal voltage range, the plant retains the reactive power of the grid. If LoM occurs, the reactive excitation power is only supplied by the excitation capacitor. Shortly after the LoM, the reactive power produced by the excitation capacitor is not only used to excite the generator but also supplies the reactive power of the load so that there is a change in the direction of the reactive power flow in the point of common coupling (PCC). Reactive power flow changes are used to detect LoM. LoM events are detected only by looking at changes in flow direction, no longer dependent on the magnitude of the reactive power that flows. The direction change of the reactive power flow is detected by manipulating the multiplication of instantaneous voltage and current.

\section{MATERIAL AND METHOD}

The system under study which refers to the IEEE 1547 standard, is shown in Fig. 1. The power system is composed of DG generators, loads, and grids. The DG generator is connected to the main grid through PCC (point of common coupling). In this paper, the DG generator consists of SEIG and excitation capacitors. The SEIG is a $500 \mathrm{~W}, 380 \mathrm{~V}, 50$ $\mathrm{Hz}$ squirrel-cage induction generator. Machine parameters and magnetization curves are obtained from measurements carried out at the laboratory of Transmission and Distribution of DTETI FT UGM, Yogyakarta, Indonesia. Machine parameters and magnetization curves are shown in the Appendix.

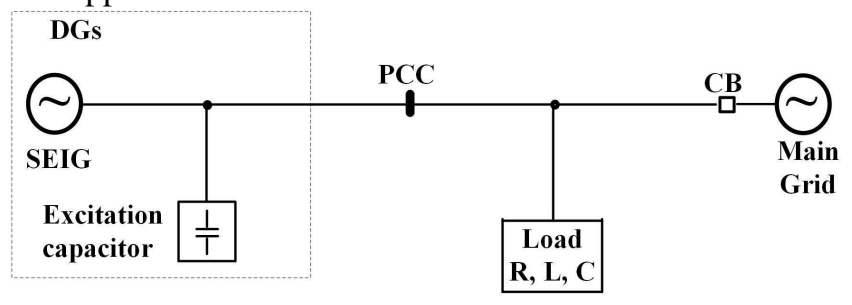

Fig. 1 The power system under study

\section{A. Excitation Capacitor Sizing Strategy}

When the generator is connected to the grid, the voltage and frequency are determined by the voltage and frequency of the grid. The relationship between the reactive power of the excitation and the voltage at a particular frequency is seen in the $\mathrm{Q}_{\text {magnetiziation }} \mathrm{V}$ curve. Fig. 2 shows a $\mathrm{Q}_{\text {magnetization }} \mathrm{V}$ curve at the frequencies of $50 \mathrm{~Hz}$ and $51 \mathrm{~Hz}$. The $50 \mathrm{~Hz}$ $\mathrm{Q}_{\text {magnetization }} \mathrm{V}$ curve was obtained from measurements on 3phase squirrel-cage induction generator, $380 \mathrm{~V}, 50 \mathrm{~Hz}, 500$ $\mathrm{W}$, while the $51 \mathrm{~Hz} \mathrm{Q}_{\text {magnetization }} \mathrm{V}$ curve was obtained from numerical simulation using SIMULINK-Matlab based on 50 $\mathrm{Hz} \mathrm{Q}_{\text {magnetization }} \mathrm{V}$ curve. The data of voltage and current measurements representing the magnetization curves are shown in Appendix.

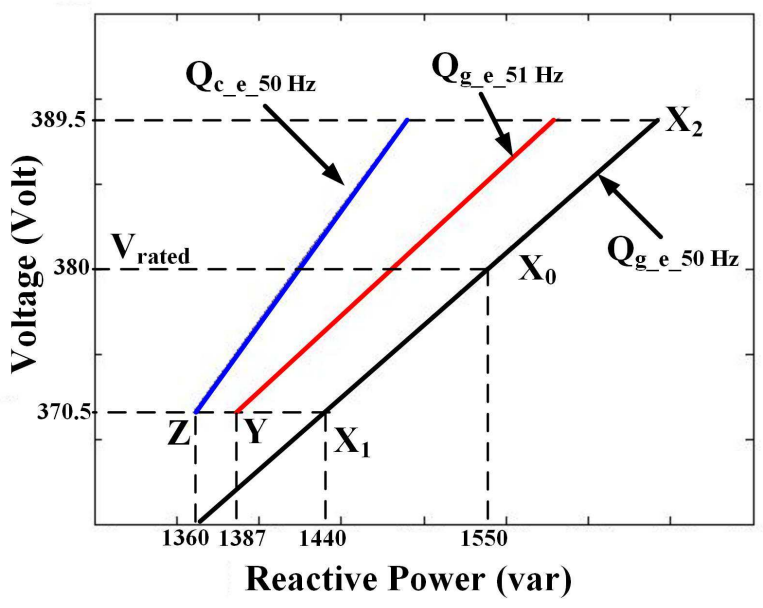

Fig. 2 A Q $\mathrm{Q}_{\text {magnetization }} \mathrm{V}$ curve of SEIG 500W, 3-phase, $380 \mathrm{~V}$

By IEEE 1547 standards, DG is not allowed to trigger a voltage fluctuation of $\pm 0.05 \mathrm{pu}$. For the determination of the excitation capacitor, a voltage range of $50 \%$ of the standard or $\pm 0.025 \mathrm{pu}$ is required, in order to guarantee that the application of this method does not cause greater fluctuations than the standard provisions. Point $\mathrm{X}_{1}$ is the operating point at a voltage of $370.5 \mathrm{~V}$ or $0.975 \mathrm{pu}$, while point $\mathrm{X}_{2}$ is the operating point at a voltage of $389.5 \mathrm{~V}$ or $1.025 \mathrm{pu}$. The operating point at the rating voltage (380 volts) is $\mathrm{X}_{0}$.

Typically, the excitation capacitor is determined at point $\mathrm{X}_{0}$, having 1550 var, so that all the reactive power produced by the capacitor flows to the generator. If the operating point shifts to point $\mathrm{X}_{1}$, the reactive power produced by the capacitor is greater than the reactive power for the excitation of the generator, so some of the reactive power will flow from the capacitor to the grid. Conversely, if the operating point shifts to point $\mathrm{X}_{2}$, the capacitor's reactive power is less than the reactive power to excite the generator, so the grid supplies the reactive power to the generator. If the base of the operating voltage rating point determines the capacitor, then the direction of reactive power flow in PCC depends on the voltage of the distribution line.

If the generator is operated on $\mathrm{X}_{2}$ and the reactive power generated by the capacitor is less than the reactive power of the generator excitation, then the grid always supplies reactive power to the generator. However, a large reactive power flow will have a negative impact, i.e., the increased voltage drop across the network and an increase in power losses. Therefore, the excitation capacitor is determined in such a way that: 
1. under normal conditions, the grid always supplies reactive power to the generator,

2. if a stand-alone (intentional islanding) operation is needed, the reactive power of the capacitor can excite the generator so that it operates at a voltage of $0.9 \mathrm{pu}$ to $1.05 \mathrm{pu}$, and at frequencies of $49 \mathrm{~Hz}$ up to $51 \mathrm{~Hz}$,

3 . the power factor generator (generator and capacitor) at full load must be greater than 0.9 lagging currents so that the reactive power flow from the grid is quite small.

If the generator operates at point $X_{1}$, the reactive power of the required excitation generator is $\mathrm{Q}_{\mathrm{g}_{\mathrm{e}}}$. The capacitor is designed to produce a reactive power of $\mathrm{Q}_{\mathrm{c}_{-} \mathrm{e}}$ less than $\mathrm{Q}_{\mathrm{g} \_\mathrm{e}}$ so that the grid supplies the reactive power of $Q_{\text {grid_e }}$ according to equation 1 .

$Q_{g_{-} e}=Q_{c_{-} e}+Q_{g_{\text {rid }} e}$

If LoM occurs, then there is no reactive power supply from the grid $\left(\mathrm{Q}_{\text {grid }}=0\right)$. The operating point will move to any point with a frequency greater than $50 \mathrm{~Hz}$ due to the reduced reactive power of the excitation that flows into the generator. If the load power factor at LoM is 1 then the new operating voltage is fixed, but with a larger frequency. In this paper, it was proposed that the operating point after the LoM be the point $\mathrm{Y}$ on the $\mathrm{Q}_{\text {magnetization }} \mathrm{V}$ curve for the frequency of $51 \mathrm{~Hz}\left(\mathrm{Q}_{\mathrm{g} \_\mathrm{e} \_51} \mathrm{~Hz}\right.$ curve in Fig. 1). The required excitation capacitor was obtained by converting the reactive power of the generator excitation at point $\mathrm{Y}$ for a frequency of $51 \mathrm{~Hz}$ to a frequency of $50 \mathrm{~Hz}$ with equation 2 .

$Q_{c_{-} e}=Q_{Y_{-} 51 H_{z}} x \frac{50}{51}=1387 \times \frac{50}{51}=1360$ var

In the operating voltage range $1 \pm 0.025 \mathrm{pu}$, the reactive power produced by the capacitor is shown on the $\mathrm{Q}_{\mathrm{c} \_\mathrm{e} \_50 \mathrm{~Hz}}$ curve in Fig. 2. The $Q_{\text {c_e } \_50 H z}$ curve is always to the left of the $\mathrm{Q}_{\mathrm{g} \_\mathrm{e} \_50 \mathrm{~Hz}}$ curve so that the grid will always supply reactive power to the generator under normal operating conditions with minimum values of 80 var or $5.6 \%$ of the reactive power required by the generator (equation 3 ). The reactive power flow will decrease if the operating point moves toward $X_{2}$. If the generator operates off-grid (intentional islanding) with resistive loads, then the generator will operate at point $\mathrm{Z}$, i.e. at a voltage of $365 \mathrm{~V}$ $(0.96 \mathrm{pu})$ at a frequency of $50 \mathrm{~Hz}$. The operating point $\mathrm{Z}$ still qualifies for off-grid operation. The proposed capacitor size in general form is $94 \%$ of the reactive power required by the generator when operating at a voltage of $0.975 \mathrm{pu}$ (equation 4).

$$
\begin{aligned}
Q_{\text {grid } \_ \text {min }} & \left(\frac{Q_{X 1}-Q_{Y_{-} 50 H z}}{Q_{X 1}}\right) 100 \% \\
& =\left(\frac{1440-1360}{1440}\right) 100 \%=5.6 \%
\end{aligned}
$$

$Q_{c_{-} e}=0.94 x Q_{g_{-} 0.975} \mathrm{pu}_{-} 50 \mathrm{~Hz}$

\section{B. Loss-of-Mains Detection}

LoM detecting method proposed in this paper are classified as local and passive. Parameters measured are voltage and current at PCC. This technique was developed on the basis that the load in the distribution network is always inductive. Although there is a capacitor in the distribution network, the capacitor is designed to improve the load power factor to about 0.9 .

The power flow and phasor diagram in PCC are shown in Fig. 3. The real power flow at PCC is from the generator to grid, and reactive power flows from the grid to the plant. Therefore, the current at PCC leads the voltage. The angle between voltage and current $(\alpha)$ depends on $Q_{\text {grid_e }}$, i.e. the difference between the reactive power of the generator excitation and the reactive power produced by the capacitor.

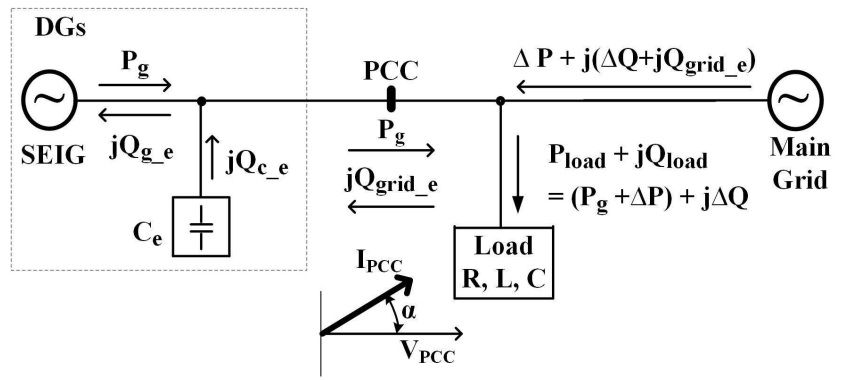

Fig. 3 Power flow and phasor diagram at normal condition

In the case of LoM, the reactive power to excite the generator is reduced because there is no reactive power flow from the grid. The reactive power for the excitation of the generator is obtained only from the excitation capacitor. The reactive power produced by the excitation capacitor flows to the generator and also to the load through the PCC. The active and reactive power flow at PCC is unidirectional, i.e. from the power plant to load. Therefore, the current at PCC lags behind the voltage. The angle between voltage and current $(\beta)$ depends on the reactive power required by the load. Fig. 4 shows the power flow and phasor diagram in PCC. In the event of a LoM:

1. The reactive power flow from the grid is disconnected,

2. Some of the reactive power of the excitation capacitor flows into the network. The direction of the reactive power flow at PCC is the opposite to the direction of the one under normal conditions,

3. The reduced reactive power of the generator excitation causes the voltage to drop. The reduced voltage causes the absorbed power of the load to decrease. The reduced load power causes the rotation of the rotor to increase so that the generator generates a larger voltage. Power and voltage swings will continue to the new operating point,

4. The new operating point depends both on changes in active power $(\Delta \mathrm{P})$ and reactive power $(\Delta \mathrm{Q})$. 


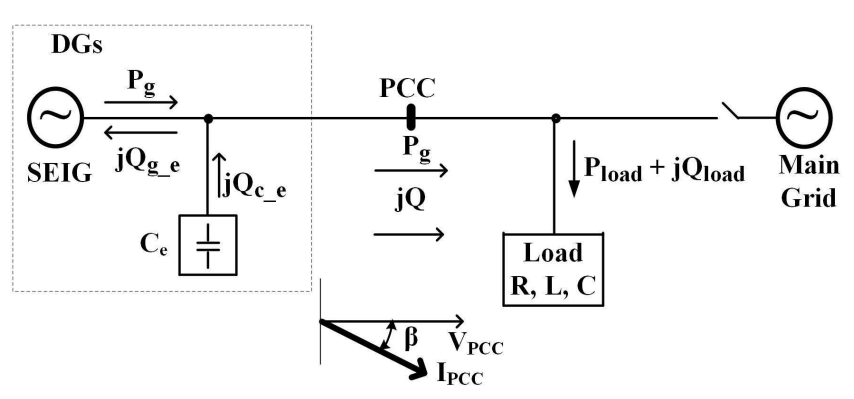

Fig. 4 Power flow and phasor diagram at LoM condition

A change in the direction of the reactive power flow is proposed to be used to detect the occurrence of LoM. Changes in the direction of the reactive power flow can be indicated by the phase change of the current, i.e., from the change of the leading current into the one of lagging current. The direction change of the reactive power flow is detected by calculating the real part of the voltage and current multiplication, which is shifted forward to $90^{\circ}$. Under normal conditions, the real part of the voltage and shifted current multiplication $\left(\mathrm{Q}_{\mathrm{d}}\right)$ will be negative (equation 5), whereas, under LoM, $\mathrm{Q}_{\mathrm{d}}$ will be positive (equation 6).

$$
\begin{aligned}
& Q_{d}=\operatorname{Re}\left(V \angle 0^{\circ} x I_{\text {lead }}^{90^{\circ}} \angle\left(\alpha+90^{\circ}\right)\right)<0 \text { normal } \\
& Q_{d}=\operatorname{Re}\left(V \angle 0^{\circ} x I_{\text {lag }}^{90^{\circ}} \angle\left(\beta+90^{\circ}\right)\right)>0 \text { LoM }
\end{aligned}
$$

The negative or positive value of the $Q_{d}$ is proposed to be used to detect the occurrence of LoM regardless of the magnitude of $\mathrm{Q}_{\mathrm{d}}$. The way is more straightforward and more accessible than the way commonly used in directional reactive power relay.

\section{RESULTS AND DISCUSSION}

To test the LoM detection method, the power system in Fig. 3 and Fig. 4 were simulated using SIMULINK-Matlab. The power system was composed of DG generators, loads, and grids. The configuration refers to the IEEE 1547 Standard. In this paper, the DG generator consists of SEIG and excitation capacitors. SEIG was simulated using mathematical model used in SIMULINK, while the machine parameters used were based on the induction machine measurement that was available in the laboratory of Transmission and Distribution of DTETI FT UGM. Machine parameter values are shown in the Appendix. Loads were modeled as constants impedance. The LoM event was simulated by opening $\mathrm{CB}$ so that the main grid was disconnected. Since SEIG always needed reactive power and distribution network loads were always inductive, then the $\Delta \mathrm{Q}$ was always positive, which means the reactive power of the load was always fed from the grid.

In this simulation, also it was studied relay function either voltage or frequency. The common settings are shown in Table I [19].

LoM simulations were performed on various scenarios. The output power of the generator was $500 \mathrm{~W}(1 \mathrm{pu})$ and the generator voltage was $0.975 \mathrm{pu}$ (point $\mathrm{X}_{1}$ in Fig. 2). The lowest load was $250 \mathrm{~W}$ and gradually raised up to $1000 \mathrm{~W}$ (2 $\mathrm{pu}$ ), on load power factor $0.8,0.9$, and 0.99. Each scenario was simulated for the nominal capacitor (1550 var) and the proposed capacitor (1360 var). It is shown in Table II. $\Delta \mathrm{P}$ is the real power that flows from the grid to the load. If $\Delta \mathrm{P}$ is negative, then the real power flowing from the generator to the grid is $\Delta \mathrm{P} . \Delta \mathrm{Q}$ is the reactive power that flows from the grid to the load.

TABLE I

RELAY SETTING

\begin{tabular}{|ll|r|r|r|}
\hline \multicolumn{1}{|c|}{ Function } & Setting range & \multicolumn{2}{c|}{$\begin{array}{c}\text { Recommended } \\
\text { settings }\end{array}$} \\
\hline Rise-in-voltage & $\mathrm{U}>$ & $1.00-1.30 \mathrm{Un}$ & $1.20 \mathrm{Un}$ & $\leq 100 \mathrm{~ms}$ \\
\hline Under volatge & $\mathrm{U}<$ & $0.10-1.00 \mathrm{Un}$ & $0.80 \mathrm{Un}$ & $1 \mathrm{~s}$ \\
\hline $\begin{array}{l}\text { Rise-in- } \\
\text { frequency }\end{array}$ & $\mathrm{f}>$ & $50.0-52.0 \mathrm{~Hz}$ & $51.5 \mathrm{~Hz}$ & $\leq 100 \mathrm{~ms}$ \\
\hline $\begin{array}{l}\text { Under } \\
\text { frequency }\end{array}$ & $\mathrm{f}<$ & $47.5-50.0 \mathrm{~Hz}$ & $47.5 \mathrm{~Hz}$ & $\leq 100 \mathrm{~ms}$ \\
\hline
\end{tabular}

In scenario 1 , the load was $250 \mathrm{~W}(0.5 \mathrm{pu})$ with a power factor of 0.80 or the reactive load power is 188 var. The generator supplied $250 \mathrm{~W}$ to the load and supplied $250 \mathrm{~W}$ to the grid $(\Delta \mathrm{P}=-250 \mathrm{~W})$. The reactive power of the load was fed by the grid ( $\Delta \mathrm{Q}=188$ var). Therefore, in the event of a $\mathrm{LoM}$, the value of $\Delta \mathrm{P}$ was $-250 \mathrm{~W}$ and $\Delta \mathrm{Q}$ was 188 var (refer to Fig. 2). For $\mathrm{C}_{\mathrm{e}}=1360$ var (scenario $1 \mathrm{C}_{1}$ ), voltage, frequency, and $\mathrm{Q}_{\mathrm{d}}$ in PCC are shown in Fig. 5. The LoM occurred at $t=2 \mathrm{~s}$. Shortly after the LoM, the generator power was greater than the load so that the frequency rose, followed by the increase of voltage. Since the load was a constant impedance, the load power rose proportionally to the square of the voltage. Frequency and voltage rise to the steady state point, which was when there was power balance between generator output power and load.

The frequency touched the upper boundary value after $145 \mathrm{~ms}$ (Fig. 5.a), while the voltage at $224 \mathrm{~ms}$ (Fig. 5.b). $\mathrm{Q}_{\mathrm{d}}$ changed the sign at $10 \mathrm{~ms}$ after LoM (Fig. 5.c). In this scenario, the LoM event could be detected by frequency relays, voltage relays and by $\mathrm{Q}_{\mathrm{d}}$, at different speeds. $\mathrm{Q}_{\mathrm{d}}$ detected LoM faster than both frequency and voltage relays.

TABLE II

\begin{tabular}{|c|c|c|c|c|c|}
\hline \multirow{2}{*}{$\begin{array}{l}\text { Scenar } \\
\text { io }\end{array}$} & \multicolumn{3}{|c|}{ Load } & \multirow{2}{*}{$\begin{array}{l}\Delta \mathrm{P} \\
(\mathrm{W})\end{array}$} & \multirow{2}{*}{$\begin{array}{c}\Delta \mathrm{Q} \\
(\mathrm{var})\end{array}$} \\
\hline & $\begin{array}{c}\mathrm{P} \\
(\mathrm{W})\end{array}$ & $\begin{array}{c}\mathrm{Q} \\
\text { (var) }\end{array}$ & Pf & & \\
\hline 1 & 250 & 188 & 0.80 & -250 & 188 \\
\hline 2 & 250 & 121 & 0.90 & -250 & 121 \\
\hline 3 & 250 & 36 & 0.99 & -250 & 36 \\
\hline 4 & 375 & 282 & 0.80 & -125 & 282 \\
\hline 5 & 375 & 182 & 0.90 & -125 & 182 \\
\hline 6 & 375 & 54 & 0.99 & -125 & 54 \\
\hline 7 & 500 & 376 & 0.80 & 0 & 376 \\
\hline 8 & 500 & 242 & 0.90 & 0 & 242 \\
\hline 9 & 500 & 72 & 0.99 & 0 & 72 \\
\hline 10 & 625 & 469 & 0.80 & 125 & 469 \\
\hline 11 & 625 & 302 & 0.90 & 125 & 302 \\
\hline 12 & 625 & 89 & 0.99 & 125 & 89 \\
\hline 13 & 750 & 563 & 0.80 & 250 & 563 \\
\hline 14 & 750 & 363 & 0.90 & 250 & 363 \\
\hline 15 & 750 & 108 & 0.99 & 250 & 108 \\
\hline 16 & 1000 & 620 & 0.80 & 500 & 620 \\
\hline 17 & 1000 & 485 & 0.90 & 500 & 485 \\
\hline 18 & 1000 & 143 & 0.99 & 500 & 143 \\
\hline
\end{tabular}

SCENARIO OF SIMULATIONS 


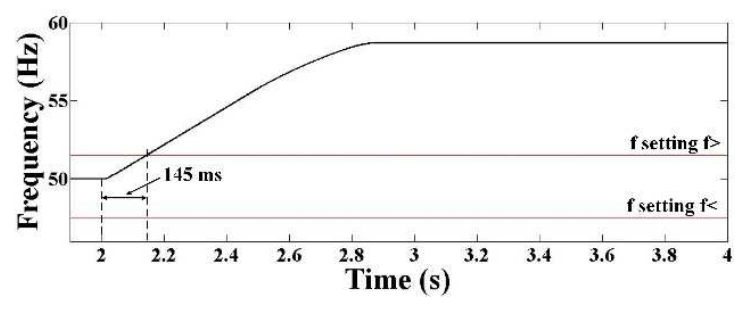

(a) Frequency

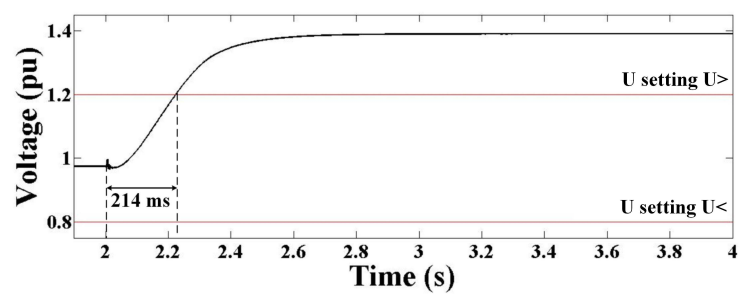

(b) Voltage

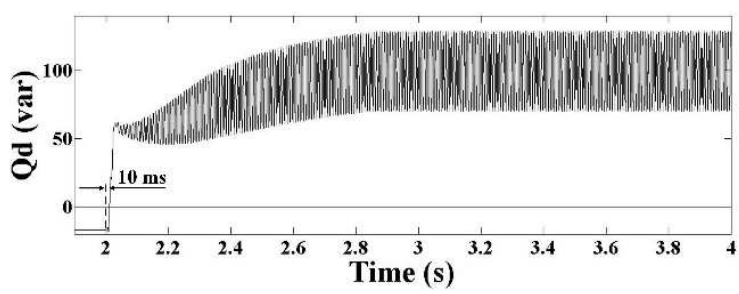

(c) $Q_{d}$

Fig. 5 LoM at $\Delta \mathrm{P}=250 \mathrm{~W}, \Delta \mathrm{Q}=188 \operatorname{var}\left(\right.$ Scenario $\left.1 . \mathrm{C}_{1}\right)$

TABLE III

Operation Time $\left(\mathrm{C}_{0}=1550\right.$ var, $\mathrm{C}_{1}=1360$ var $)$

\begin{tabular}{|r|r|r|r||r|r|r|r|}
\hline \multirow{2}{*}{$\begin{array}{c}\text { Sce- } \\
\text { nario }\end{array}$} & \multicolumn{3}{|c|}{$\begin{array}{c}\text { Operation time } \\
(\mathrm{ms})\end{array}$} & $\begin{array}{r}\text { Sce- } \\
\text { nario }\end{array}$ & \multicolumn{3}{|c|}{$\begin{array}{c}\text { Operation time } \\
(\mathrm{ms})\end{array}$} \\
\cline { 2 - 4 } & $\mathrm{Q}_{\mathrm{d}}$ & $\mathrm{UF} /$ & $\mathrm{UV} /$ & & $\mathrm{Q}_{\mathrm{d}}$ & $\mathrm{UF} /$ & $\mathrm{UV} /$ \\
& & $\mathrm{OF}$ & $\mathrm{OV}$ & & & $\mathrm{OF}$ & $\mathrm{OV}$ \\
\hline $1 \mathrm{C}_{0}$ & $\mathrm{x}$ & 145 & 157 & $10 \mathrm{C}_{0}$ & $\mathrm{x}$ & 214 & $\mathrm{x}$ \\
$\mathrm{C}_{1}$ & 10 & 143 & 224 & $\mathrm{C}_{1}$ & 10 & 200 & $\mathrm{x}$ \\
\hline $2 \mathrm{C}_{0}$ & $\mathrm{x}$ & 146 & 226 & $11 \mathrm{C}_{0}$ & $\mathrm{x}$ & 291 & $\mathrm{x}$ \\
$\mathrm{C}_{1}$ & 10 & 144 & 214 & $\mathrm{C}_{1}$ & 10 & 240 & $\mathrm{x}$ \\
\hline $3 \mathrm{C}_{0}$ & $\mathrm{x}$ & 145 & 200 & $12 \mathrm{C}_{0}$ & $\mathrm{x}$ & $\mathrm{x}$ & $\mathrm{x}$ \\
$\mathrm{C}_{1}$ & 10 & 145 & 190 & $\mathrm{C}_{1}$ & 10 & $\mathrm{x}$ & $\mathrm{x}$ \\
\hline $4 \mathrm{C}_{0}$ & $\mathrm{x}$ & 157 & $\mathrm{x}$ & $13 \mathrm{C}_{0}$ & $\mathrm{x}$ & 245 & $\mathrm{x}$ \\
$\mathrm{C}_{1}$ & 10 & 155 & $\mathrm{x}$ & $\mathrm{C}_{1}$ & 10 & 226 & $\mathrm{x}$ \\
\hline $5 \mathrm{C}_{0}$ & $\mathrm{x}$ & 167 & $\mathrm{x}$ & $14 \mathrm{C}_{0}$ & $\mathrm{x}$ & 338 & $\mathrm{x}$ \\
$\mathrm{C}_{1}$ & 10 & 158 & $\mathrm{x}$ & $\mathrm{C}_{1}$ & 10 & 256 & $\mathrm{x}$ \\
\hline $6 \mathrm{C}_{0}$ & $\mathrm{x}$ & 200 & $\mathrm{x}$ & $15 \mathrm{C}_{0}$ & $\mathrm{x}$ & $\mathrm{x}$ & $\mathrm{x}$ \\
$\mathrm{C}_{1}$ & 10 & 175 & $\mathrm{x}$ & $\mathrm{C}_{1}$ & 10 & $\mathrm{x}$ & $\mathrm{x}$ \\
\hline $7 \mathrm{C}_{0}$ & $\mathrm{x}$ & 184 & $\mathrm{x}$ & $16 \mathrm{C}_{0}$ & $\mathrm{x}$ & 318 & 29 \\
$\mathrm{C}_{1}$ & 10 & 155 & $\mathrm{x}$ & $\mathrm{C}_{1}$ & 10 & 257 & 30 \\
\hline $8 \mathrm{C}_{0}$ & $\mathrm{x}$ & 220 & $\mathrm{x}$ & $17 \mathrm{C}_{0}$ & $\mathrm{x}$ & 362 & 34 \\
$\mathrm{C}_{1}$ & 10 & 158 & $\mathrm{x}$ & $\mathrm{C}_{1}$ & 10 & 330 & 40 \\
\hline $9 \mathrm{C}_{0}$ & $\mathrm{x}$ & $\mathrm{x}$ & $\mathrm{x}$ & $18 \mathrm{C}_{0}$ & $\mathrm{x}$ & $\mathrm{x}$ & 62 \\
$\mathrm{C}_{1}$ & 10 & 257 & $\mathrm{x}$ & $\mathrm{C}_{1}$ & 10 & $\mathrm{x}$ & 52 \\
\hline & & & & & & & \\
\hline
\end{tabular}

Table III shows the operating time of LoM detection using $Q_{d}$, the frequency relay, and the voltage relay for 2 excitation capacitor values, i.e. nominal $\left(\mathrm{C}_{0}=1550\right.$ var $)$ and proposed $\left(C_{1}=1360\right.$ var $)$. It can be seen in Table III that $Q_{d}$ cannot detect the LoM (x) if it uses nominal excitation capacitors $\left(\mathrm{C}_{0}\right)$, and can detect all LoM events if using the proposed excitation capacitor $\left(\mathrm{C}_{1}\right)$. Frequency relay failed to detect LoM in scenario 9 when using $\mathrm{C}_{0}$ but succeeded when using $\mathrm{C}_{1}$. Frequency relay failed to detect LoM in scenarios 12,15 , and 18 , both when using $\mathrm{C}_{0}$ and $\mathrm{C}_{1}$. The voltage relay fails to detect the LoM in scenarios 4 to 15 , either when using $\mathrm{C}_{0}$ or $\mathrm{C}_{1}$. In general, frequency relays are better to detect LoM than voltage relays. In scenarios 12 and 15, both the frequency relay and the voltage relay fail to detect the LoM, while Qd succeeded in detecting the LoM.

\section{CONCLUSIONS}

In this paper, it was proposed how to determine the size of the excitation capacitor as a prerequisite for using the reactive power flow change $\left(\mathrm{Q}_{\mathrm{d}}\right)$ as a LoM detector. The detection of the direction of reactive power flow was done by manipulating the multiplication of instantaneous voltage and current. Under normal conditions, the real part of the voltage and shifted current multiplication $\left(\mathrm{Q}_{\mathrm{d}}\right)$ was negative, whereas, under LoM, $\mathrm{Q}_{\mathrm{d}}$ was positive. The negative or positive value of the $\mathrm{Q}_{\mathrm{d}}$ was proposed to be used to detect the occurrence of LoM regardless of the magnitude of $Q_{d}$. The effectiveness of LoM detection was simulated on the inductive load and compared with both the voltage relay and the frequency relay. With the proposed method in this paper, the change of $\mathrm{Q}_{\mathrm{d}}$ from negative to positive could be used to detect all the LoM events. The disadvantage of this method was not able to detect the LoM if the combined distribution network and load were capacitive. However, in general, the combined network and load are always inductive. Changes in the sign of $\mathrm{Q}_{\mathrm{d}}$ can be used as the principal detector of LoM, whereas the frequency relay and voltage relay are functioned as a backup.

\section{APPENDIX}

\section{Machine Parameter}

$\begin{array}{llr}\text { Rated power } & = & 500 \mathrm{~W} \\ \text { Rated voltage } & = & 380 \mathrm{~V} \\ \text { Rated current } & = & 2.26 \mathrm{~A} \\ \text { Rated frequency } & = & 50 \mathrm{~Hz} \\ \mathrm{R}_{\mathrm{S}} & = & 4.30 \Omega \\ \mathrm{R}_{\mathrm{r}}{ }^{\prime} & = & 4.29 \Omega \\ \mathrm{X}_{\mathrm{ls}} & = & 3.99 \Omega \\ \mathrm{X}_{\mathrm{lr}} & = & 6.00 \Omega \\ \mathrm{R}_{0} & = & 659.97 \Omega \\ \mathrm{X}_{\mathrm{m}}, & = & 117.42 \Omega \\ \mathrm{H} & = & 0.13 \mathrm{~W} . \mathrm{s} / \mathrm{VA}\end{array}$

\section{Magnetization Characteristic of The Machine}

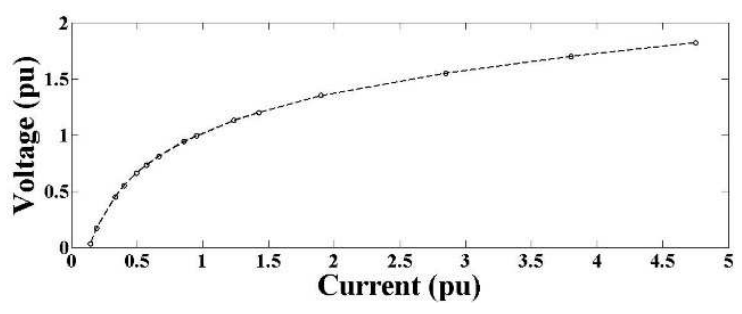

Fig. 6 Magnetization characteristic curve of the machine 
TABLE IV

MAGNETIZATION CHARACTERISTIC

\begin{tabular}{|r|r|}
\hline Voltage $(\mathrm{pu})$ & Current $(\mathrm{pu})$ \\
\hline 0.03 & 0.14 \\
\hline 0.17 & 0.19 \\
\hline 0.45 & 0.33 \\
\hline 0.55 & 0.40 \\
\hline 0.66 & 0.49 \\
\hline 0.73 & 0.57 \\
\hline 0.81 & 0.67 \\
\hline 0.94 & 0.86 \\
\hline 0.99 & 0.95 \\
\hline 1.13 & 1.24 \\
\hline 1.20 & 1.43 \\
\hline 1.35 & 1.90 \\
\hline 1.55 & 2.85 \\
\hline 1.70 & 3.80 \\
\hline 1.82 & 4.75 \\
\hline
\end{tabular}

\section{ACKNOWLEDGMENT}

We gratefully acknowledge the funding from USAID through the SHERA program - Centre for Development of Sustainable Region (CDSR).

\section{REFERENCES}

[1] N. Jenkins, R. Allan, J. B. Ekanayake, G. Strbac, Embedded Generation, London, U. K, Inst. Elect. Eng., 2010.

[2] G. Pepermans, J. Driesen, D. Haeseldonckx, R. Belmans and W. D'haeseleer, "Distributed generation: definition, benefits, and issue," Elsevier Energy Policy, vol. 33, pp. 787-798, 2005.

[3] D. Levy, "Stand alone induction generators," Elect. Power Syst. Res., vol. 41, pp. 191-201, 1997.

[4] R. C. Bansal, "Three-Phase Self-Excited Induction Generators: An Overview," IEEE Transactions on Energy Conversion, vol. 20, No. 2, pp. 292-299, June 2005.

[5] D. Bejmert, T. S. Sidhu, "Investigation into Islanding Detection with Capacitor Insertion-based Method," IEEE Trans. On Power Del., vol. 29, no. 6, pp. 2485-2492, Dec. 2014.

[6] I. Mazhari, H. Jafarian, J. Enslin, S. Bhowmik, "Locking Frequency Band Detection Method for Islanding Protection of Distribution Generation," IEEE Journal of Emerging and Selected Topics in Power Electronics, vol. 5, No. 3, pp. 1385-1396, Sept 2017.

[7] Interconnecting Distributed Resources with Electric Power Systems, IEEE Std 15472003.

[8] A. Khamis, H. Shareef, E. Bizkevelci, T. Khatib, "A Review of islanding detection techniques for renewable distributed generation systems," Elsevier, Renewable and Sustainable Energy Reviews, vol.28, pp.483-493, 2013

[9] P. Mazat, Z. Chen, B. Bak-Jensen, "Review of Islanding Detection Methods for Distributed Generation," Electric Utility Deregulation and Restructuring and Power Technologies, DRPT, pp. 2743-2748, Nanjing China, 6-9 April 2008.

[10] K. A. Ropp, N. Sabhah, "Using Power Carrier Communications to Prevent Islanding," in Proc. 28th IEEE Photovoltaic Specialist Conference, pp. 1675-1678, 2000.

[11] W. Wang, J. Kliber, G. Zhang, W. Xu, B. Howell, T. Palladino, “A Power Line Signaling Based Technique for Anti-Islanding Protection of Distributed Generators-Part I: Scheme and Analysis," IEEE Tran. Power Delivery, vol. 22, no. 3, pp. 1758-1766, July 2007.

[12] W. Wang, J. Kliber, G. Zhang, W. Xu, B. Howell, T. Palladino, "A Power Line Signaling Based Technique for Anti-Islanding Protection of Distributed Generators-Part II: Field Test Results," IEEE Tran. Power Delivery, vol. 22, no. 3, pp. 1767-1772, July 2007.

[13] J. S. Hwang, J. E. Kim, "Islanding Detection Method of Distributed Generation Units Connected To Power Distribution System," in IEEE Power System Technology Conference, pp. 643-647, 2000.

[14] B. Fox, P. O'Kane, "Loss of Mains Detection for Embedded Generation by System Impedance Monitoring," in Developments in Power System Protection, Conference Publication No. 434, CIEE, 1997, 25-27th March 1997.

[15] B. Wen, D. Boroyevich, R. Burgos, Z. Shen, P. Mattavelli, "Impedance-Based Analysis of Active Frequency Drift Islanding Detection for Grid-Tied Inverter System," IEEE Transaction on Industry Applications, vol. 52, no. 1, Jan/Feb 2016.

[16] J. Sung-Il, K. Kwang-Ho, "An Islanding Detection Method for Distributed Generations Using Voltage Unbalance and Total Harmonic Distortion of Current," IEEE Transaction on Power Delivery, vol. 19, no. 2, pp. 745-752, April 2004.

[17] H. Laaksonen, "Advanced Islanding Detection Functionality for Future Electricity Distribution Networks," IEEE Transaction on Power Delivery, vol. 28, no. 4, pp. 2056-2064, October 2013.

[18] P. C. M. Meira, A. P. Grilo, W. Freitas, J. C. M. Vieira, "Investigation of the Islanding Detection of Induction Generators," Power \& Energy Society General Meeting, 2009. PES '09. IEEE, Calgary, AB, Canada, 26-30 July 2009.

[19] I. Abdulhadi, Xinyao Li, F. Coffele, P. Crolla, A. Dysko, C. Booth, G. Burt, International White Book on DER Protection: Review and Testing Procedures, Glasgow, U.K., Institute for Energy and Environment, 2012.

[20] J. G. Trapp, J. B. Parizzi, F. A. Farret, Á.B. Serdotte, A. J. Longo, "Stand alone self-excited induction generator with reduced excitation capacitors at fixed speed," in Proc. Power Electronics Conference (COBEP), 2011 Brazilian, p. 955-962.

[21] C. Salimikordkandi, T. Sürgevil, "Modeling and Analysis of SelfExcited Induction Generator with Fixed Capacitor Excitation and Shunt Voltage Regulation," in Proc. Power Electronics and Motion Control Conference and Exposition (PEMC), 2014, p. 149-155 